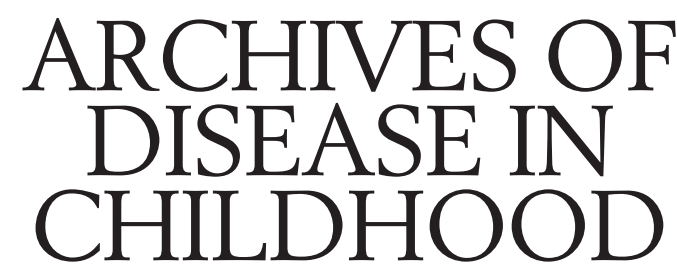

The Fournal of the Royal College of Paediatrics and Child Health

\title{
Annotation
}

\section{"Can I have a letter for the housing, doctor?"}

Doctors are often asked to appeal to housing departments to take a child's ill health into consideration for rehousing points. Less frequently they are asked to provide evidence on behalf of a patient who is suing a housing authority for compensation because it is believed that poor housing conditions have caused a deterioration in their health. Children with asthma or other respiratory symptoms are the subject of this review.

It is generally accepted that poor housing is associated with poor health. ${ }^{1}$ However, it is far harder to ascribe a specific illness such as asthma to factors believed to be adverse, such as dampness and mould. In a litigation case, it is not enough to say "it is well known that poor housing is related to poor health and no family, healthy or otherwise, should live in a damp and mouldy house". What is required is a clear statement on whether "this child's asthma was caused or exacerbated by damp and mould".

First, the diagnosis of asthma. A prospective litigant may be referred for assessment of chest disease and an opinion about whether this has been caused or exacerbated by adverse housing conditions. Quite often, in spite of a good history of respiratory symptoms, the physical examination, respiratory function tests, and evidence of atopy are negative or inconclusive. The report of the assessment could read, "although there is evidence of dampness and mould in this child's home and reported respiratory symptoms consistent with asthma, I can find no objective evidence of asthma in this child". Strachan has questioned the reliability of symptom reporting ${ }^{2}{ }^{3}$ in studies that purport to demonstrate a relation between housing conditions and respiratory symptoms; if respondents know the purpose of a questionnaire they are more likely to provide a biased response. The difficulty of diagnosing asthma has been highlighted on many occasions. ${ }^{45}$

Second, for the child with definite asthma what are the relative contributions of dampness, passive smoking, allergen exposure, fumes from gas cookers, and so on? A letter that reads, "Poor housing, household pets, passive cigarette smoking, ... are all believed to be independently associated with respiratory symptoms. ${ }^{6}$ Please take these factors into account when considering this family for rehousing," may not help the family to move house. Parental smoking could well put paid to any chance of a move. There is a lot of literature on the subject and much disagreement about the contribution of indoor pollutants, ${ }^{7}$ including passive smoking. ${ }^{8}$ These issues are further discussed in a recent study of indoor environment and its relation to respiratory symptoms in children living in the Scottish Highlands. ${ }^{9}$ No relation between reported symptoms and poor housing (dampness, mould), parental cigarette smoking, or household pets could be identified. The only relation identified was moving house, something previously noted. ${ }^{10}$ This relation could work against an application for a move.

In contrast, a case-control study of hospitalised patients with asthma aged 5-40 years living in a Scottish inner city showed that the patients were two to three times more likely to live in damp housing. ${ }^{11}$ There was a weak but significant dose response relation between asthma severity and the severity of dampness and mould. Advantages of this study are that objective measurements of airflow obstruction and damp and mould were made. To try to remove reporting bias, patients were asked to complete a questionnaire before they knew their houses would be examined. In fact, dampness tended to be underreported by the asthmatics.

Third, what is it about damp housing that could cause respiratory ill health? The house dust mite (which thrives in high humidity), mould, ${ }^{12}$ gas fumes, ${ }^{13}$ and so on have all been implicated. In a condition such as asthma, early exposure to a high house dust mite concentration may have sensitised a child with an atopic disposition. ${ }^{14}$ Asthma morbidity from house dust mite sensitivity may not be dose related. In Sydney, Australia house dust mite concentrations do not differ in the homes of children with and without asthma. ${ }^{15}$ It could be argued that children, especially those with an atopic disposition, should not be housed in poor accommodation in the first place. It is too late after the asthma has developed. "Mrs X is expecting a baby. Her house is damp (which encourages house dust mite infestation) and mouldy. Please consider the family for rehousing before the baby is born, especially as the family is highly atopic." This seems to be no less reasonable an appeal than appeals after a child has developed respiratory symptoms.

The strong association between cigarette smoking and heart and lung disease arguably satisfies Hill's requirements for "causal inference". ${ }^{16}$ The evidence is not yet consistent or strong enough to propose a similar link between household dampness, mould, house dust mite exposure, and respiratory disease in children. Rather than concentrating on what is considered unhealthy, perhaps a more helpful approach would be to consider what is healthy in house design to advise builders and planning officers. Obviously houses are constructed to try to avoid dampness, but can we manage without carpets, which harbour house dust mites, and balance adequate insulation with good ventilation to avoid condensation? In North 
American inner city areas cockroach sensitivity is more strongly associated with asthma than either house dust mites or cat dander. ${ }^{17}$ Cockroaches prefer warm dry conditions. In efforts to provide dry warm housing we must make sure we do not create an environment that encourages alternative allergens.

Meanwhile, the reports we write for our patients will undoubtedly be influenced by our sympathy for the family, our political beliefs, and how strongly we are persuaded by the current arguments. Lanes ${ }^{18}$ has proposed that causal inference is not a matter for scientists but lies strictly in the domain of public opinion. Rothman ${ }^{19}$ believes that this philosophy " . . has the advantage of not putting scientists in the awkward position of being advocates for a particular theory". There are huge numbers of damp houses, especially in the inner cities of northern Europe, and huge numbers of children with respiratory complaints. There is no consensus of professional opinion about the effect of poor housing and the indoor environment on children's respiratory symptoms. Maybe, if we are honest, that is all we can say.

SHEILA MCKENZIE

Queen Elizabeth Hospital for Children,

Royal Hospitals Trust,

Hackney Road, London E2 8PS, UK

email:mckenzie@rhtch.demon.co.uk

1 Lowry S. Housing and health 1991. London: BMJ Publishing Group, 1991. 2 Strachan DP. Damp housing and childhood asthma: validation of reporting of symptoms. BMF 1988;297:1223-6.

3 Strachan DP, Sanders CH. Damp housing and childhood asthma; respiratory effects of indoor air temperature and relative humidity. $\mathcal{F}$ Epidemiol Community Health 1989;43:7-14.

4 Magnus P, Jaakola JJK. Secular trend in the occurrence of asthma among children and young adults: critical appraisal of repeated cross sectional surveys. BMF 1997;314:1795-9.

5 Taylor DR. Making the diagnosis of asthma. BMF 1997;315:4-5.

6 Lindfors A, Wickman M, Hedlin G, Pershagen G, Rietz H, Nordvall SL. Indoor environmental risk factors in young asthmatics: a case-control study. Arch Dis Child 1995;73:408-412.

7 Pludy. Arch Dis Child 1995;73:408-412. Engl F Med 1997;336:1382-4.

8 Hood RD, Wu JM, Witorsch RJ, Wirorsch P. Environmental tobacco smoke exposure and respiratory health in children: an updated critical review and analysis of the epidemiological literature. Indoor Environment 1992;1:19-35.

analysis of the epidemiological literature. Indoor Environment 1992;1:19-35. Scottish Highlands. Arch Dis Child 1997;76:22-6.

10 Hughes CH, Baumer LH. Moving house: a risk factor for the development of childhood asthma? BMF 1995;311:1069-70

11 Williamson IJ, Martin CJ, McGill G, Monie RD, Fennerty AG. Damp housing and asthma: a case-control study. Thorax 1997;52:229-34

12 Strachan DP. Moulds, mites and childhood asthma. Clin Exp Allergy 1993; 23:799-801.

13 Melia RJW, Florey CV, Chinn S. The relationship between respiratory illness in primary school children and the use of gas for cooking. I. Results from a national survey. Int f Epidemiol 1979;8:333-8.

14 Sporik R, Holgate ST, Platts-Mills TAE, Cogswell JJ. Exposure to the house-dust mite allergen (Der p I) and the development of asthma in childhood. A prospective study. N Engl F Med 1990;323:502-7.

15 Marks GB, Tovey ER, Toelle BG, Wachinger S, Peat JK, Woolcock AJ. Mite allergen (Der p 1) concentration in houses and its relation to the presence and severity of asthma in a population of Sydney schoolchildren. $\mathcal{F}$ Allergy

16 Hill AB. The environment and disease: association or causation? Proc $R$ Soc Med 1965;58:295-300.

17 Rosenstreich DL, Eggleston P, Kattan M, et al. The role of cockroach allergy and exposure to cockroach allergen in causing morbidity among inner-city children with asthma. N Engl F Med 1997;336:1356-63.

18 Lanes S. Causal inference is not a matter of science Am $\mathcal{F}$ Epidemiol 1985;122:550.

19 Rothman KJ. Causal inference in epidemiology. In: Rothman KJ, ed. Modern epidemiology. Boston: Little, Brown and Company, 1996: 14-21.

\section{Commentary}

In contrast to the perspective of the health professional, housing is the biggest single health issue on the people's agenda. In any debate with local people living in deprived areas it becomes clear that housing is seen as the major risk to health in Glasgow.-Annual report, Director of Public Health, Greater Glasgow Health Board. 1989.

McKenzie writes about requests for medical support for rehousing children with asthma or other respiratory symptoms. Such requests most often arise in relation to damp and mouldy housing, a problem common throughout the UK. A recent report by Scottish Homes found that $25 \%$ of
Scottish housing had damp and condensation problems. The situation is compounded because many of these homes are also hard to heat. Poor housing is frequently found in inner city areas and housing schemes where smoking, unemployment, socioeconomic deprivation, and pet ownership all co-exist. This combination of factors often leads to medical symptoms being attributed to the sufferer's lifestyle - as one Glasgow campaigner put it, "Blame the victim syndrome is the worst disease we know."

Paediatricians are well aware of the association between passive smoking and respiratory symptoms in children. They may be less aware of the substantial epidemiological evidence of an association between respiratory symptoms of wheeze, cough, and nasal discharge (particularly in children), and living in damp and mouldy housing. ${ }^{1-10}$ Because the evidence comes from epidemiological studies of populations, the difficulties diagnosing asthma highlighted by McKenzie are academic. Indeed, a specific association with asthma has only recently been confirmed by two casecontrol studies. ${ }^{79}$ In Kenya, Mohamed et al found that asthmatic children were more likely to live in damp and mouldy housing with an odds ratio of 4.9 for dampness in the child's sleeping area. ${ }^{9}$ Williamson et al studied 102 people with asthma aged 5-44 years, and included independent assessment of both dampness and objective measures of lung function. ${ }^{7}$ Asthma was associated with living in damp housing and there appeared to be a dose response relation.

\section{Association or causation-does it matter?}

The published evidence satisfies many of Hill's criteria for a causal relation. ${ }^{11}$ The association has been strong and consistent with odds ratios around 2 . Indeed, the effect of damp and mould has been said to be comparable in size to the effect of passive smoking. ${ }^{2}$ The association has remained after adjusting for confounders such as smoking, poverty, and housing tenure, and there has been evidence of a dose response. ${ }^{712}$

Hill himself noted that the decisive question is whether the frequency of an undesirable action will be influenced by a change in the environmental feature. It has been argued that the case against damp and mouldy housing is sufficiently clear that further research is unnecessary. Nevertheless, some important questions remain. First, are respiratory symptoms and asthma associated with damp and mouldy housing reversed by rehousing in dry accommodation? Is asthma triggered or exacerbated by poor housing? A randomised trial of rehousing is unlikely but upgrading occurring in many areas may provide opportunities for longitudinal studies with "waiting list" designs to assess health changes.

Second, there is continuing debate about the mechanism of the association. The original hypothesis that mould allergy drives the association seems unlikely. Current work is directed more to the effects of fungal toxins and house dust mite.

Third, McKenzie highlights the need to consider healthy house design. Architects now accept that many problems experienced by tenants were caused by genuine faults in house design. The projected repair costs are huge-the Scottish bill is estimated at $£ 6$ billion. It would clearly be very helpful to know which intervention (for example, elimination of mould, central heating, double glazing) would provide a "best buy" for health gain.

\section{Is it worth suing the housing authority?}

Paediatricians may be asked to provide medical evidence about the health effects of poor housing. In civil actions, the standard of proof is "the balance of probabilities", broadly equating to a relative risk of 2 -that is, exposure more than doubles the risk. ${ }^{13}$ This is essentially the 
situation for damp and mouldy housing. Courts are increasingly accepting that damp and mouldy housing does "cause" respiratory illness. However, litigation remains very uncommon. Most cases are settled out of court for no more than a few thousand pounds. Unfortunately, even success in court does not usually lead to rehousing, which is what most families want. Nevertheless, successful litigation is likely to increase the political pressure to improve the housing stock.

\section{Personal practice}

In my experience, unprompted requests for letters to housing authorities about damp and mouldy housing are uncommon. Mention of home damp and mould is usually only elicited on direct questioning. Interestingly, some studies have noted that patients tend to underreport damp and mould. ${ }^{714}$ Often, families have worked to maintain their homes in as good a condition as possible, at considerable personal effort and expense. They frequently have instituted other steps such as anti-house dust mite measures or removing animals. If the diagnosis is asthma, and symptoms are severe, then I would write a specific letter to the housing authority about the adverse effects of damp and mouldy housing on the child's respiratory health, emphasising the importance of dry housing. Supporting documentation such as photographs of the mould damage may be useful.

Does writing make a difference? Housing associations seem to vary in their attitude and response to such letters. A clear and specific letter from a hospital consultant stating that a child's respiratory condition is serious and is likely to have been made worse by adverse housing conditions may lead to a housing association at least making a detailed assessment. If repairs are needed these may be instigated; if the house is beyond repair, priority for rehousing may be awarded. Translating priority into rehousing often takes years. Frustration at the refusal of housing authorities to act or even to acknowledge that problems exist drives some families to litigation. With this in mind, families should be encouraged to obtain supporting documentation such as photographs, and to keep careful records, all of which may be helpful if legal action results.

Perhaps, in the end the people are right. Dampness is an important public health issue. Medical support can make a difference.

Department of Child Health,

JAMES PATON

Royal Hospital for Sick Children

Yorkhill, Glasgow G3 8S7, UK

email:7.Y.Paton@clinmed.gla.ac.uk

1 Dales RE, Zwanenburg H, Burnett R, Franklin CA. Respiratory health effects of home dampness and molds among Canadian children. Am f Epidemiol 1991;134:196-203.

2 Brunekreef B, Dockery DW, Speizer FE, Ware JH, Spengler JD, Ferris BG. Home dampness and respiratory morbidity in children. Am Rev Respir Dis Home dampness and

3 Platt SD, Martin CJ, Hunt SM, Lewis CW. Damp housing, mould growth, and symptomatic health state [see comments]. BMF 1989;298:1673-8.

4 Strachan DP, Sanders CH. Damp housing and childhood asthma; respiratory effects of indoor air temperature and relative humidity. $f$ Epidemiol Community Health 1989;43:7-14.

5 Hyndman SJ. Housing dampness and health amongst British Bengalis in east London. Soc Sci Med 1990;30:131-41.

6 Martin CJ, Platt SD, Hunt SM. Housing conditions and ill health. BMF 1987;294:1125-7.

7 Williamson IJ, Martin CJ, McGill G, Monie RDH, Fennerty AG. Damp housing and asthma: a case-control study. Thorax 1997;52:229-34.

8 Lindfors A, Wickman M, Hedlin G, Pershagen G, Rietz H, Nordvall SL. Indoor environmental risk factors in young asthmatics: a case-control study. Arch Dis Child 1995;73:408-12.

9 Mohamed N, Ng'ang'a L, Odhiambo J, Nyamwaya J, Menzies R. Home environment and asthma in Kenyan school-children: a case-control study. Thorax 1995;50:74-8.

10 Yang C, Chiu J, Kao W. Damp housing conditions and respiratory symptoms in primary school children. Pediatr Pulmonol 1997;24:73-7.

11 Hill AB. The environment and disease: association or causation? Proc $R$ Soc Med 1965;58:295-300.

12 Strachan DP. Damp housing and childhood asthma: validation of reporting of symptoms. BMf 1988;297:1223-6.

13 Meeran R. Scientific and legal standards of proof in environmental injury cases. Lancet 1992;339:671-2.

14 Brunekreef B, van Strien RT, Verhoeff AP, van Wijnen JH. Responder bias in assessment of home dampness [abstract]. Am Rev Respir Dis in assessment 